\title{
Garnet trace element concentrations as indicators for diamond grades
}

\author{
Greg L. Melton, Thomas Stachel, Steven Creighton \\ Earth and Atmospheric Sciences, University of Alberta, Edmonton, Canada
}

\section{Introduction}

Research aimed at evaluating the economic potential of diamond deposits is constantly evolving. The goal of finding an efficient means to predict the diamond potential of a kimberlite occurrence has led to a wide diversity of methods unequal with respect to reliability, expense, or time intensiveness. Using trace element ratios of xenocryst garnets, we have developed a simple and effective tool for evaluating the potential grade of diamond deposits.

\section{Garnet chemistry database}

We compiled a database of 6395 published and unpublished garnet trace element analyses comprising 502 analyses of garnet inclusions in diamonds and 5893 garnet xenocrysts from kimberlites and lamproites representing 18 cratons. Kimberlite diamond grades range from 0 to 400 carats per hundred ton (cpht) as reported in press releases, assessment reports and other literature. Major element information was recorded when available and garnet classifications range from G0-1, 3-5, 9-12 using the scheme of Grütter et al. (2004). Garnet trace element concentrations were normalized to $\mathrm{C} 1$ chondrite.

Kimberlite diamond grades were subdivided into three populations: (i) low-grade for kimberlites with $<10$ cpht or reported as non-economic, (ii) medium-grade for kimberlites reported to have grades from 11 to 75 cpht, and (iii) high-grade for kimberlites with $75+$ cpht. Garnet inclusions in diamond were treated as a separate "ideal" subpopulation. All analyses were filtered to include only lherzolitic (G9) and harzburgitic (G10) garnets and the final database includes 1377 garnets.

\section{Chemical correlations to grade}

Garnet trace element concentrations from any single source show large variations and, therefore, overlaps are observed for all four of the populations defined above. Nevertheless, discriminating properties exist allowing for the use of garnet xenocryst trace element composition to be used as a predictor of diamond grade. Overall, garnet inclusions in diamonds show the greatest normalized light rare earth element $\left(\operatorname{LREE}_{\mathrm{N}}\right)$ enrichment and the strongest heavy rare earth element $\left(\mathrm{HREE}_{\mathrm{N}}\right)$ depletion of all samples (Stachel et al., 1997). The LREE enrichment is best seen in $\mathrm{Ce}_{\mathrm{N}}$ to $\mathrm{Nd}_{\mathrm{N}}$ and the HREE depletion is most noticeable in the heaviest rare earth elements $\mathrm{Yb}_{\mathrm{N}}$ and $\mathrm{Lu}_{\mathrm{N}}$. Middle rare earth element concentrations $\left(\mathrm{MREE}_{\mathrm{N}}\right)$ show no systematic variations. These compositional characteristics are related to strongly sinusoidal $\mathrm{REE}_{\mathrm{N}}$ patterns that are characteristic for the majority of fluid metasomatised inclusions in diamonds (Stachel et al., 1998, 2004). Thus, a field of ideal garnet trace element composition can be identified on a plot of $\mathrm{Nd} / \mathrm{Ce}$ (LREE enrichment) vs. Nd/Lu (HREE depletion). As shown in Figure 1, garnets included in diamond have $\mathrm{Nd} / \mathrm{Lu}$ between 4 and 800 and $\mathrm{Nd} / \mathrm{Ce}$ from 0.2 to 5 . These ratios are indicators of specific metasomatic processes that either promote diamond growth or, alternatively, are diamond destructive (Stachel et al., 1998, 2004).

This "ideal" field incorporates $81 \%$ of all diamond inclusions, $73 \%$ of all garnet analyses from high-grade deposits, $61 \%$ from all medium-grade deposits and $20 \%$ from all low-grade and non-economic deposits. These results indicate that xenocryst garnets with high $\mathrm{Nd} / \mathrm{Lu}$ and low $\mathrm{Nd} / \mathrm{Ce}$ are characteristic for high-grade diamond deposits.

\section{Example and evaluation}

A statistical analysis of these results supports the observation that garnet xenocrysts with high $\mathrm{Nd} / \mathrm{Lu}$ and low $\mathrm{Nd} / \mathrm{Ce}$ are indicative of higher diamond grades in kimberlite. A single factor analysis of variance (ANOVA) test of the individual $\mathrm{Nd} / \mathrm{Lu}$ and $\mathrm{Nd} / \mathrm{Ce}$ shows that high, medium, low-grade deposits and diamond inclusions have a probability of $\ll 1 \times 10^{-10}$ of representing the same population $(\alpha=0.01)$. This indicates that none of the four garnet subpopulations are related to any of the others with $>99 \%$ confidence. 


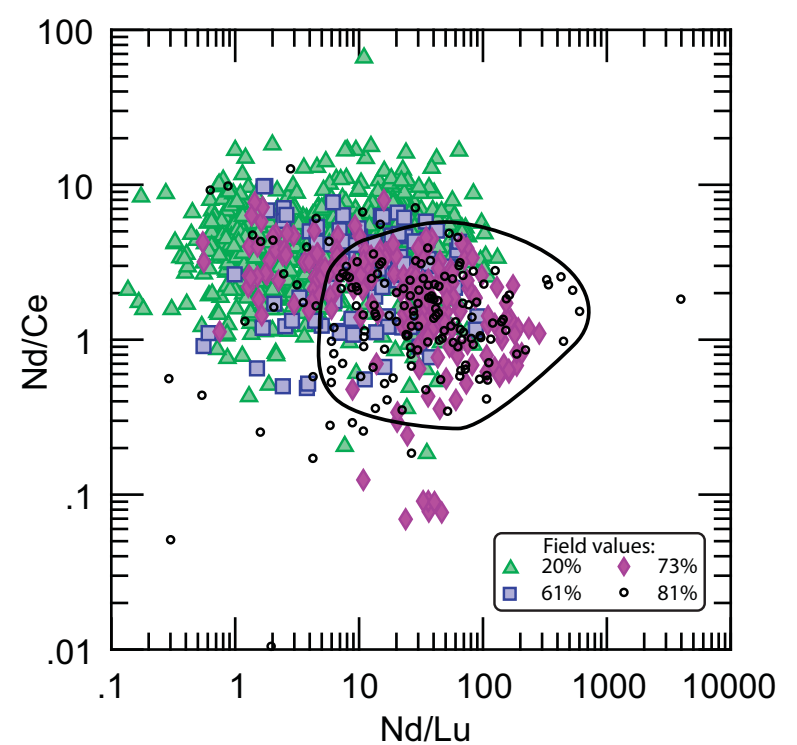

$\triangle$ Low grade (<10 cpht)

$\checkmark$ High grade $(75+$ cpht $)$

$\square \quad$ Medium grade (10-75 cpht)

- Diamond inclusions

Figure $1 \mathrm{Log} / \log$ plot of $\mathrm{Nd} / \mathrm{Ce}$ vs. $\mathrm{Nd} / \mathrm{Lu}$. The four different symbols represent the data subpopulations discussed in the text. Proportions of each subpopulation that fall within the diamond inclusion field (black circle) are also given.

To further investigate the utility of this method, a case study was undertaken to show the differences between four deposits. Garnet xenocrysts from two high-grade deposits, Diavik and Snap Lake (Slave Craton), were plotted with two low-grade occurrences - the Sextant Rapids and Isson Creek kimberlites (Superior Craton and North American Craton, respectively). There is a clear distinction between garnet xenocryst compositions from the high-grade and low-grade kimberlites (Figure 2). As predicted from the preceding data, the low-grade kimberlites have garnet xenocrysts with higher $\mathrm{Nd} / \mathrm{Ce}$ and lower $\mathrm{Nd} / \mathrm{Lu}$ whereas the highgrade kimberlites have moderate to low $\mathrm{Nd} / \mathrm{Ce}$ and moderate to high $\mathrm{Nd} / \mathrm{Lu}$.

\section{Discussion and Conclusion}

By using the field defined in $\mathrm{Nd} / \mathrm{Ce}$ and $\mathrm{Nd} / \mathrm{Lu}$ space by the composition of garnets included in diamonds, the economic potential of a kimberlite deposit can be predicted with confidence. Xenocryst garnets with compositions that overlap this field are strong signals for a high-grade deposit. Garnet analyses the plot close to or even outside of the field, however, are more ambiguous and should be interpreted cautiously with respect to diamond potential.

This trace element compositional field can be used in conjunction with more conventional exploration techniques including electron microprobe analyses and geotherm information to maximize the amount of information revealed by mantle xenocrysts for successful diamond prospecting.

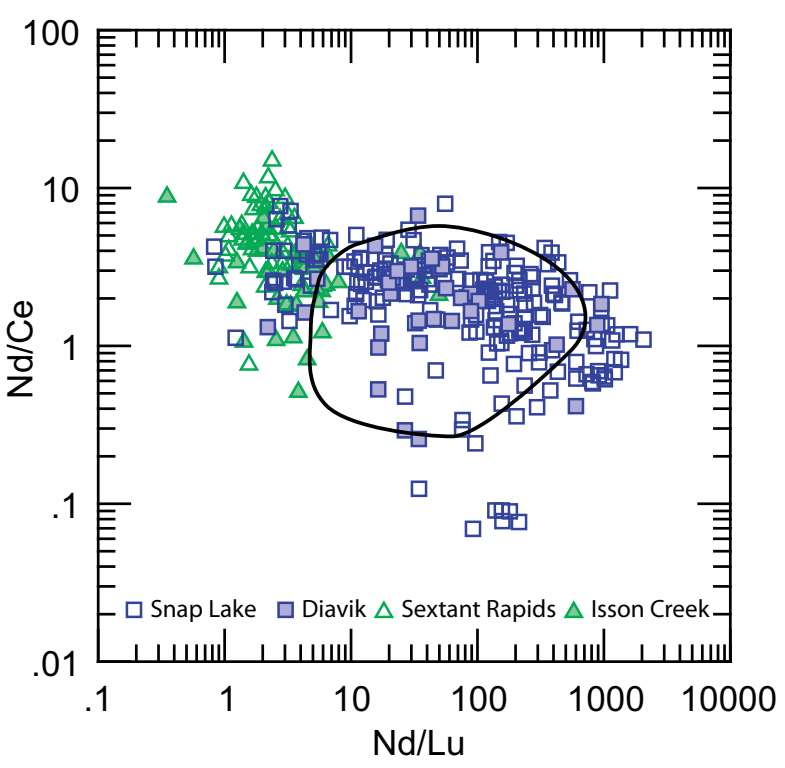

Figure 2 Comparison plot of selected diamond occurrences. Triangles (open and filled) represent the low-grade deposits and squares (open and filled) represent the high-grade deposits.

\section{References}

Grütter, H.S., Gurney, J.J., Menzies, A.H., Winter, F., 2004. An updated classification scheme for mantlederived garnet, for use by diamond explorers. Lithos, 77, 841-857.

Stachel, T., Harris, J.W., 1997. Diamond precipitation and mantle metasomatism - evidence from the trace element chemistry of silicate inclusions in diamonds from Akwatia, Ghana. Contributions to Mineralogy and Petrology, 129, 143-154.

Stachel, T., Viljoen, K.S., Brey, G., Harris, J.W., 1998. Metasomatic processes in lherzolitic and harzburgitic domains of diamondiferous lithospheric mantle: REE in garnets from xenoliths and inclusions in diamonds. Earth and Planetary Science Letters, 159, 1-12.

Stachel, T., Aulbach, S., Brey, G.P., Harris, J.W., Leost, I., Tappert, R., Viljoen, K.S., 2004. The trace element composition of silicate inclusions in diamonds: a review. Lithos, 77, 1-19. 